\title{
Correction to: Determination of Menbutone in Bovine Milk and Meat Using Micellar Liquid Chromatography: Application to Injectable Dosage Forms
}

\author{
F. Belal ${ }^{1} \cdot$ Sawsan A. Abd El-Razeq ${ }^{2} \cdot$ Manal M. Fouad $^{2,4} \cdot$ S. Zayed $^{3} \cdot$ Fatma A. Fouad $^{2}$
}

Published online: 15 December 2017

(C) Springer Science+Business Media, LLC, part of Springer Nature 2017

Correction to: Food Anal. Methods (2016) 9(3):638-645 https://doi.org/10.1007/s12161-015-0230-7

The original version of this article unfortunately contained a mistake. Affiliation 4 should be included for Manal M. Fouad.

The online version of the original article can be found at https://doi.org/ 10.1007/s12161-015-0230-7.

S. Zayed

s1zayed@yahoo.com

1 Pharmaceutical Analytical Chemistry Department, Faculty of Pharmacy, University of Mansoura, Mansoura 35516, Egypt

2 Analytical Chemistry Department, Faculty of Pharmacy (Girls), Al-Azhar University, Cairo, Egypt

3 Unit of Drug Analysis, Faculty of Pharmacy, University of Mansoura, Mansoura 35516, Egypt

4 October University for Modern Sciences and Arts, Cairo, Egypt 